\title{
Cardiac Hydatidosis
}

\author{
Walla Luay Al_Falluji ${ }^{a} \quad$ Ammar Naif $^{\text {b }} \quad$ Wissam Al Obaidy $^{c}$ \\ ${ }^{a}$ College Of Medicine, Universityof Babylon, Babil, Iraq. \\ ${ }^{b, c}$ Ibn Al_Bitar Cardiac Center, Baghdad,Iraq \\ Walla_alfalluji@yahoo.com
}

Submission date:- 6/9/2018 Acceptance date:- 7/10/2018 Publication date:- 22/1/2019

Keywords: Cardiac Hydatid, Hydatid cyst ,Rupture cyst

\begin{abstract}
Cardiac hydatid disease is rare, occurring in about $2 \%$ of the patients, the disease usually involves the myocardium and is associated with a wide spectrum of presentations, hence the patients may be asymptomatic or may present with a serious condition like severe valvular dysfunction, congestive heart failure, pulmonary embolism or conductive disturbances. Full histories, a proper examination of the chest, ECG, CXR, Echo cardiography, cardiac catheterization, CT scan of the chest and immunoblot tests are essential diagnostic tools. Fifteen patients diagnosed preoperatively as having cardiac hydatid cysts were involved in this retrospective study. There was neither sex predilection nor any age limit for the disease. Any part of the heart could be involved; but the Left ventricle was the commonest site. Many patients included in the study were associated with extracardiac involvement especially the liver. Removal of the cyst(s) surgically stay the treatment of choice.
\end{abstract}

\section{Introduction}

Cardiac hydatid disease is rare, occurring in about $2 \%$ of cases. When it occure, the cysts are usually intramyocardium of the left ventricle. However, the right ventricle or atrium may also be involved[1]. Cardiac hydatid disease may cause valvular dysfunction, conductive disturbances, congestive heart failure and it may cause a potentially fatal pathology[2].

\section{Life Cycle of the parasite and Pathological course:}

Hydatid disease is caused by the cestode tapeworm granulosus and tapeworm multilocularis. The life cycle involves primary and therefore the intermediate class hosts [3]. Dogs area unit the same old primary host and therefore the host is typically a sheep or cow, however sometimes human. Within the abdomen the eggs hatch and therefore the embryos cross the internal organ mucous membrane, enter the blood vessels and bodily fluid system[4]. Liver and lungs along filter the bulk (approximately 85\%-90\%) of the embryos. Via circulation just about $10 \%-15 \%$ could reach alternative organs together with the internal organ chambers, interventricular septum and therefore the serous membrane $(0.02 \%-2 \%)[5]$.

Hydatid cysts locations within the pneumonic arteries square measure exceptional. Whenever the embryo settles, it forms a cyst cyst. The cyst wall secreted by the embryo consists of 2 layers, the outer ectocyst and also the inner endocyst. The inner endocyst is termed the germinal layers and it's the important layer of the cyst to blame for the formation of broad capsule, scolices, fluid within the cyst. The outer layer is termed the laminated membrane. The cyst is encompassed by an animal tissue known as the pericyst that could be a part of the host[ 6]. Granular deposits square measure found to settle at very cheap of fluid and square measure known as cyst sands that square measure composed of broad capsules, free scolices and loose hooklets [7].The cysts square measure most often placed within the cavum septum and left cavum wall. giant cysts within the serosa will cause extraneous compression of the guts.The cysts might degenerate and calcified, type female offspring cysts or rupture into the cavum chambers causes pneumonic or general embolizations or hypersensitivity reaction re. Rupture of the pericardiac cyst will turn out carditis, pericardiac effusion and pericardiac constriction[8].

The cyst of echinococcal infection will occur any wherever within the heart. the foremost common website is that theventricle owing to embolization through the left anterior descendent artery. Most lesions are seen within theinterventricular septum and therefore the left chamber wall. The cyst might prolapse through the tricuspidate and mitral valves during a fashion like benign tumour. In some cases, the differentiation between a benign tumour and therefore the cyst are created solely when surgical removal [8]. 


\section{Clinical Findings:}

Most patients with Echinoccocus infections square measure well, particularly within the long early stages. Embryos square measure cornered in numerous target organs particularly the liver and lungs, however additionally within themuscles, kidneys, heart, brain, bones and alternative organs[9 ].Embryos that don't seem to bedestroyed by the body's defenses could transform cyst cysts that grow and cause pain, occlusion disfunction in keeping with the or space of the affected organ(s).cardiopulmonary cysts could grow for several years before inflictingpain, palpitations, dyspnea, cough, hemoptysis . internal organ cyst could exist as long as twenty years before changing into giant enough to cause pressurerelated issues like hypochondriac pain, nausea, cirrhosis, jaundice, and alternative liver manifestations [10 ]

Cysts in the brain, kidneys and other organs also cause signs and symptoms related to these organs, hence the patient with involvement of other organs beside the heart will present with cardiac and extra cardiac manifestations[10].Cardiac cyst diseases are also symptomless or could gift with clinical findings; relying upon 2 factors; the localization and therefore the range of the cysts; these cysts could cause obstruction within the chamber of the center or induce physical phenomenon disturbances. Rupture of the viscus cyst cysts could end in hypersensitivity reaction, pneumonic and general embolisms [11].

\section{Diagnosis}

To establish the diagnosis; full history should be taken from the patient, proper examination of the chest and other parts of the body. Then many investigations should be done; ECG findings could be normal; or Twave abnormalities; CXR may disclose an abnormal contour or calcified rounded mass in any region of the heart[12]. Cardiac catheterizations to rule out coronary artery occlusion and pressure changes in the chambers. Immunoblot (western blot) and ELISA are 50\%-56\% sensitive for cardiorespiratory cyst cyst. Once the cyst ruptures, there's AN abrupt stimulation of antibodies; but old, calcified, or dead cysts are seronegative. If the CT scan shows a cyst notwithstanding confirmation by medical science, the identification ought to be created[13 ]. Casoni test is not very reliable because of frequent false positive and false negative results. Echocardiography is a reliable technique for diagnosis of intracardiac masses, but in some cases the echocardiography may not show the multiseptate nature of echinoccocal lesions, thus echinoccocal infections should be included in the differential diagnosis of tumor like lesions of the heart.Definitive diagnosis and localization of the cysts can be achieved with echocardiography, CT scan or MRI. The cystic nature of the lesions is clearly defined by CT scan and MRI[13].

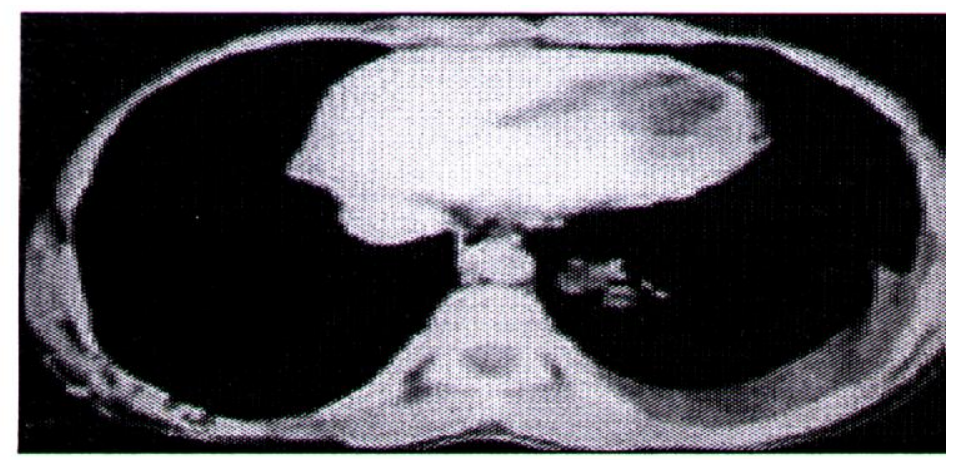

Fig. (1): CT scan of the chest shows hydatid cyst in the interventricular septum with left sided pleural effusion[12].

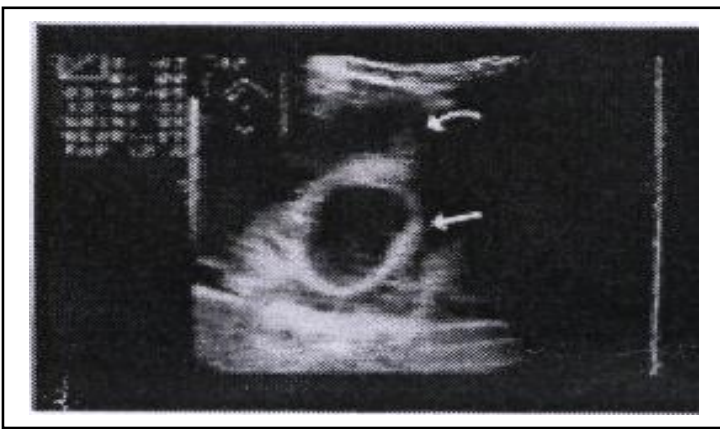

Fig.(2) - A

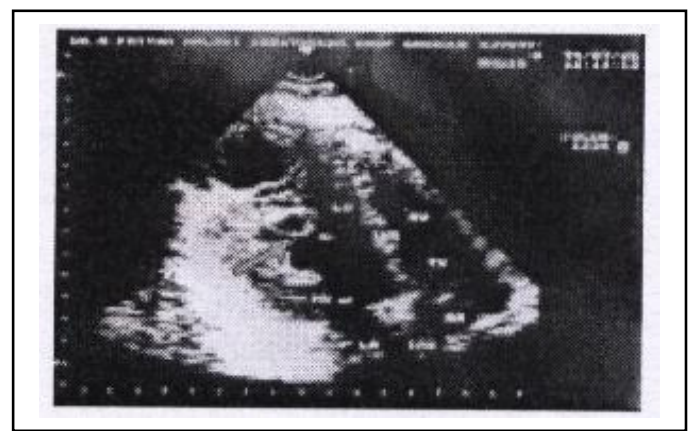

Fig.(2) - B

Fig.(2): 2-D Echocardiography view , (A) shows the cyst in the interventricular septum, (B) shows cystic lesion in the left ventricular poserolateral wall[13]. 


\section{Treatment:}

Removal of the cyst surgically stay the best treatment. It almost have disinfected of the cyst before enucleation via instillation one of the following solutions formalin, $0.5 \%$ silver nitrate solution, $30 \%$ hypertonic saline solution, $1 \%$ iodide solution or $5 \%$ cetamide solution. This precautionary measure is done to prevent spread of the infection in state of complicating cyst[14]. Unfortunately, pharmacological treatment can be very helpful and supportive if begin prior to surgery. Pharmacological management may begin by albendazol 400mg 12-hourly for three months. This line of treatment is also used for inoperable disease and to reduce the infectivity of the cysts preoperatively. Praziquantel $20 \mathrm{mg} / \mathrm{kg} 12$-hourly for 14 days kills protoscolices perioperatively[15].

\section{Patients and methods:}

A retrospective study of fifteen patients diagnosed preoperatively as having cardiac hydatid cysts was conducted in Ibn Al-Bitar Hospital for Cardiac Surgery between November 2004 and June 2016. All patients were admitted to the hospital, underwent full clinical evaluation and investigations that included: Complete hematological and biochemical tests, CXR, ECG,Echocardiography, Angiography (in some patients) and CT scan of the chest (in some patients). The details of the patients involved in the study are demonstrated in the table (1). After full evaluation being completed, all patients were explored by median sternotomy; with extracorporeal circulation (apart from only one patient, in which the hydatid cyst involved the pericardium only); aspiration of the cystic fluid; opening \& removing of the membranes \& daughter cysts; and finally closure.

Table (1) Name, age and sex distribution.

\begin{tabular}{|c|c|c|c|c|c|c|c|c|c|c|c|c|c|c|c|}
\hline \multirow[b]{2}{*}{ 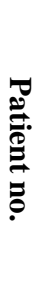 } & \multirow{2}{*}{ 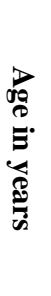 } & \multirow[b]{2}{*}{$\mathscr{\mathbb { x }}$} & \multicolumn{10}{|c|}{ Presenting symptoms } & \multirow{2}{*}{ 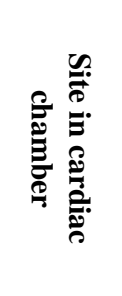 } & \multirow[b]{2}{*}{ 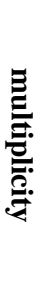 } & \multirow{2}{*}{ 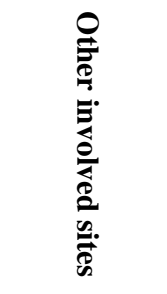 } \\
\hline & & & $\stackrel{\mathscr{0}}{0}$ & 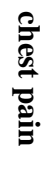 & 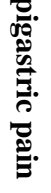 & $\frac{\pi}{3}$ & 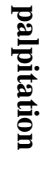 & 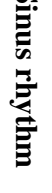 & 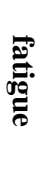 & 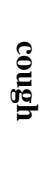 & 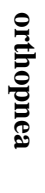 & 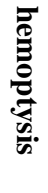 & & & \\
\hline 1 & 55 & $\mathbf{F}$ & l & I & & & & I & & & & & $\mathbf{L V}$ & & \\
\hline 2 & 58 & $\mathbf{M}$ & I & & I & & I & I & & & & & $\mathbf{R V}$ & & \\
\hline 3 & 16 & $\mathbf{M}$ & l & & & & & I & & I & & I & RA & & Lung \\
\hline 4 & 25 & $\mathbf{M}$ & 1 & & & 1 & & & & & & I & $\mathbf{R V}$ & & Lung \\
\hline 5 & 21 & $\mathbf{M}$ & I & & & & & I & 1 & 1 & & & Peri & & Lung \\
\hline 6 & 43 & $\mathbf{F}$ & & l & & & & & & I & & & Peri LV & l & \\
\hline 7 & 10 & $\mathbf{F}$ & 1 & & I & & & 1 & & & & & $\mathbf{R V}$ & & Liver \\
\hline 8 & 38 & $\mathbf{M}$ & & I & & & 1 & & & & & & IVS & & Brain \\
\hline 9 & 27 & $\mathbf{F}$ & I & I & I & & & I & & & & & $\mathbf{L V}$ & & Liver \\
\hline 10 & 34 & $\mathbf{F}$ & I & I & & & & & & I & & & $\mathbf{L V}$ & & \\
\hline 11 & 14 & M & I & I & & & & I & & & & & LV & & Liver \\
\hline 12 & 27 & M & 1 & 1 & & 1 & I & 1 & & & I & & LV & & Liver \\
\hline 13 & 28 & $\mathbf{F}$ & I & I & & & & & & & & & LA Peri & I & $\begin{array}{l}\text { Liver.kidne } \\
\text { y. brain }\end{array}$ \\
\hline 14 & 32 & $\mathbf{M}$ & & I & & & I & 1 & & & & & $\mathbf{L V}$ & & liver \\
\hline 15 & 40 & $\mathbf{F}$ & 1 & 1 & & & & 1 & & & & & IVS & & \\
\hline
\end{tabular}


7.Results:

Table 2: demonstrates the age distribution of the patients.

\begin{tabular}{|c|c|c|}
\hline Age in years & Number of patients & Percentage \% \\
\hline $10-20$ & 3 & 20 \\
\hline $21-30$ & 5 & 33.33 \\
\hline $31-40$ & 4 & 26.66 \\
\hline $41-50$ & 1 & 6.66 \\
\hline $51-60$ & 2 & 13.33 \\
\hline Total & 15 & 100 \\
\hline
\end{tabular}

Table 3: demonstrates the sex distribution of the patients.

\begin{tabular}{|c|c|c|}
\hline Sex & Number & Percentage \% \\
\hline Male & $\mathbf{8}$ & $\mathbf{5 3 . 3}$ \\
\hline Female & 7 & 47.7 \\
\hline Total & 15 & 100 \\
\hline
\end{tabular}

Table 4: demonstrates the clinical presentations

\begin{tabular}{|c|c|c|}
\hline Clinical presentation & Number & $\begin{array}{c}\text { Percentage } \\
\%\end{array}$ \\
\hline Shortness of breath & 13 & 86.6 \\
\hline Chest pain & 7 & 46.6 \\
\hline Epigastric pain & 5 & 33.3 \\
\hline Hepatosplenomegally & 2 & 13.3 \\
\hline Palpitation & 4 & 26.6 \\
\hline Sinus rhythm & 10 & 66.6 \\
\hline Fatigue & 1 & 6.6 \\
\hline Cough & 3 & 20 \\
\hline Orthopnea & 1 & 6.6 \\
\hline Hemoptysis & 2 & 13.3 \\
\hline
\end{tabular}

Table 5: demonstrates the involvement of cardiac chambers.

\begin{tabular}{|c|c|c|}
\hline Site & Number & Percentage \% \\
\hline Left ventricle & 7 & 46.6 \\
\hline Right ventricle & 3 & 20 \\
\hline Right atrium & 1 & 6.66 \\
\hline Interventricular septum & 1 & 6.66 \\
\hline Pericardium & 3 & 20 \\
\hline Left atrium & 1 & 6.66 \\
\hline
\end{tabular}

Table 6: demonstrates the operative procedures that were applied

\begin{tabular}{|c|c|c|}
\hline Operation & Number & Percentage \% \\
\hline Removal of the cyst & 14 & 93.3 \\
\hline Pericardiectomy & 1 & 6.7 \\
\hline
\end{tabular}

- 2 patients had multiple hydatid cysts involving the pericardium and other chambers $(13.3 \%)$.

- 10 patients $(66.6 \%)$ were associated with other sites involvement; most frequently the liver $(50 \%)$ and the least was the kidney $(6.6 \%)$.

\section{Discussion:}

Echinococcusis could be a wide familiar animal disease caused by cestode granuloses infection; it's a lot of frequent in some areas of the globe wherever sheep raising is common. In humans the foremost common locations of cyst cysts arthe liver $(>65 \%)$ and therefore the lungs, however; they'll be seen in any location together with the heart[16]. Internal organ hydatidosis of the center is rare, happens in zero.5 - 2 Chronicles of all infestation in humans, there doesn't seem to be of any ordinance or sex predilection at the time of presentation [17]. This coincides with this study where there was no tendency of the disease to involve specific age group; the ages of the involved patients were between 10 years and 60 years. Also; there was no 
significant sex predilection (53.3\% were males \& $47.7 \%$ were females).Cardiac hydatid cysts can involve any part of the heart; but the most common site is the left ventricle [18]. This goes with this study in which, the most common site of cardiac involvement was the left ventricle (approximately $47 \%$ of the patients).

The cysts may cause no symptoms or may produce a wide spectrum of symptoms including shortness of breath, chest pain, epigastric pain, palpitation, cough, hemoptysis, orthopnea, in addition of chamber obstruction or conductive disturbances. Complicated hydatid cyst of the heart may cause shock due to allergy and embolisms[11]. In our study the most frequent presentations were shortness of breath $(86.6 \%)$ and chest pain $(46.6 \%)$. Hydatid cyst could be multiple involving more than one part of the heart [19]. Of the fifteen cases that were included in this study, two patients had multiple hydatid cyst (13.3\%) involving the left atrium and the left ventricle in addition to the pericardium.

$(66.6 \%)$ of the patients included in the study were associated with extracardiac involvement mainly the liver (50\% of them had associated liver involvement). This coincides with what was mentioned by Beggsi (1985); the liver is the commonest associated site for cardiac hydatid cyst[Alper H 2015]. Removal of the cyst surgically stay the best solution. It carries risk of spread of the liquid which may produce allergy and a spread of scolices[4]. The logic approach to this hyperendemic disease in Iraq is prevention [20].

\section{Conclusions}

Hydatid cyst of the heart is a uncommon problem , There is no age limit, nor sex predilection for the disease,The left chamber is more frequently involved than other parts of the heart, The liver is the commonest organ to be involved in association with the heart, Definitive diagnosis and localization of the cyst can be achieved by echocardiography, CT scan and MRI, The disease could be asymptomatic or may have a wide spectrum of presentations ,Medical management can be helpful and supportive if started before surgery and the Surgery is the definitive treatment of the disease.

\section{CONFLICT OF INTERESTS}

There are no conflicts of interest.

\section{References}

[1]Ameli, M, Marborhan HA, Nauraii SS: Surgical treatment of Hydatid cyst of the heart:report of six cases. $J$ Thoracic \& cardiovas surgery; 98: 892 - 901. 2015.

[2]Beggs.I. the radiology of Hydatid disease. AJR: 1;639. 2014.

[3]Cantoni S, Frola C, Gatto R, Terzi MI etal. Hydatid cyst of the interventricular septum of heart, MRI findings. AJR: 161; 753. 2013.

[4]Alper H. , Yunten R, Sener NR. Intramural hydatid cyst of pulmonary arteries: CT and MRI findings, Eur J radiology, 666. 2015.

[5]Von sinner WN, Clark D, Sharif H: MRI findings in Hydatid disease. AJR: 157;741. 2016.

[6]Ozturk C, Balkanci F: Pulmonary arterial embolism secondary to Hydatid cyst of liver. 374. 2012

[7]chattarjee D, F sanchez, Textbook of parasitology, 12 ${ }^{\text {th }}$ edition, Calcutta, India, Chattarjee medical publishers, April;121. 2012.

[8]Masci, J. Echinococcosis, clinical advisor: instant diagnosis and treatment. St.louis: Mosby; 231. 2013.

[9]Goldsmith R; current medical diagnosis and treatment, 40 ${ }^{\text {th }}$ edition, Appleton \& Lange, New York, 1331. 2014.

[10]Masci J.; Instant diagnosis and treatment, 13th ed., St.Louis: Mosby,232. 2013.

[11]Di Bello R.;Intracardiac rupture of Hydatid cyst.New English J med. 187. 2015.

[12]Moro P. and Gilman R.;Cystic hydatid disease, $8^{\text {th }}$ ed., W. B. Saunders, Philadelphia ,875. 2014.

[13]Safioeas M., Skalkeas G.; Cardiopulmonary Hydatid disease,diagnosis and management. World journal of surgery, 23, ,85. 2015.

[14]Oliver JM, Lopez de sa, et al,. Clinical and Surgical aspects of cardiac hydtid cysts,Eur Heart J., 37. 2013. 
[15]Christopher H., Edwin R. and Nicholas A.; Principles and practice of medicine, $18^{\text {th }}$ ed., Churchill Livingstone, Philadelphia, 172. 2016.

[16]Perez-Gomez F., Duran H., Pervote L., Tamamer S., Blanes A.; Cardiac echinococcosis clinical pictures and complications.Br.heartJ. 35:1326. 2015.

[17]Kaplan M.,Demirtas M.,Cimen S.,Ozler A.;Cardiac hydatid cysts with inttracavitary expansion.Ann.Thorasic surgery. 71:1587. 2014.

[18]Kulan K.,Tuncer C.,Kulan C., et al. Cardiac hydatid cysts and contribution of magnetic resonance imaging.Acta cardiology. 50:323.2013.

[19]Kudaiberdier T., Djoshiber S.; Multiple hydatid cysts of the epicardium and pericardium. Internal $J$. cardiology. 81:265. 2014.

[20] Elhassani NB: hydatid disease in Iraq: possible to deal with, deadly to ignore. IPMJ: 3,207. 2003.

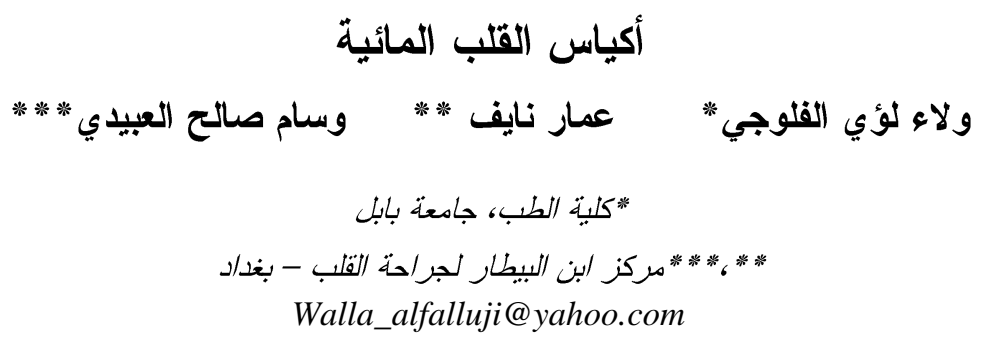

الخلاصة

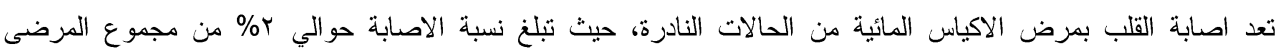

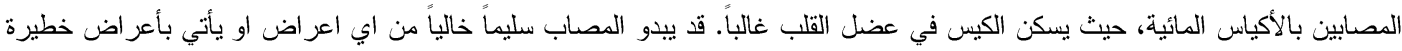

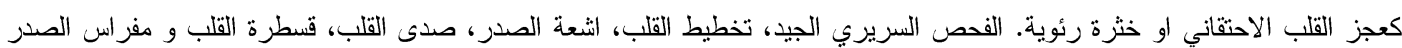

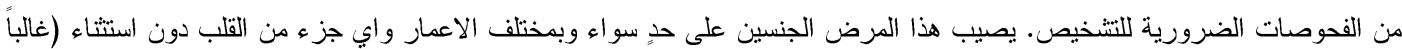

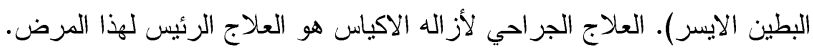
الكلمات الدالة: اكياس القلب المائية، الكيس المائي، انفجار الكيس المائي. 